\title{
Sexual harassment and assault experienced by reservists during military service: Prevalence and health correlates
}

\author{
Amy E. Street, PhD; ${ }^{1-2 *}$ Jane Stafford, PhD; ${ }^{3}$ Clare M. Mahan, PhD; ${ }^{4}$ Ann Hendricks, PhD $^{5-6}$ \\ ${ }^{1}$ National Center for Posttraumatic Stress Disorder, Department of Veterans Affairs (VA) Boston Healthcare System, \\ Boston, MA; ${ }^{2}$ Department of Psychiatry, Boston University School of Medicine, Boston, MA; ${ }^{3}$ Department of Psychol- \\ ogy, University of South Carolina Aiken, Aiken, South Carolina; ${ }^{4}$ VA Environmental Epidemiology Service, Washing- \\ ton, DC; ${ }^{5}$ VA Boston Healthcare System, Boston, MA; ${ }^{6}$ Department of Health Policy and Management, Boston \\ University School of Public Health, Boston, MA
}

\begin{abstract}
The current investigation identified the genderspecific prevalence of sexual harassment and assault experienced during U.S. military service and the negative mental and physical health correlates of these experiences in a sample of former reservists. We surveyed a stratified random sample of 3,946 former reservists about their experiences during military service and their current health, including depression, posttraumatic stress disorder, somatic symptoms, and medical conditions. Prevalence estimates and confidence intervals of sexual harassment and assault were calculated. A series of logistic regressions identified associations with health symptoms and conditions. Both men and women had a substantial prevalence of military sexual harassment and assault. As expected, higher proportions of female reservists reported sexual harassment (60.0\% vs $27.2 \%$ for males) and sexual assault (13.1\% vs $1.6 \%$ for males). For both men and women, these experiences were associated with deleterious mental and physical health conditions, with sexual assault demonstrating stronger associations than other types of sexual harassment in most cases. This investigation is the first to document high instances of these experiences among reservists. These data provide further evidence that experiences of sexual harassment and assault during military service have significant implications for the healthcare needs of military veterans.
\end{abstract}

Key words: mental health, military service, military sexual trauma, physical health, posttraumatic stress disorder, rehabilitation, reservists, sexual assault, Sexual Experiences Questionnaire, sexual harassment.

\section{INTRODUCTION}

In recent years, concerns about the high rates of sexual harassment and sexual assault experienced by members of the U.S. military during their national service have caused researchers, policymakers, and the press to pay considerable attention to this issue [1-3]. Sexual harassment, long identified as a significant occupational health concern in the civilian sector [4], is defined by the Equal Employment Opportunity Commission as "unwelcome sexual advances, requests for sexual favors, and other verbal or physical conduct of a sexual nature" that occur in a work setting [5]. The term sexual harassment encompasses

\footnotetext{
Abbreviations: $\mathrm{AOR}=$ adjusted odds ratio, CES-D $=$ Center for Epidemiologic Studies Depression Scale, CI = confidence interval, DMDC = Defense Manpower Data Center, DSM-IVTR = Diagnostic and Statistical Manual of Mental DisordersFourth Edition-Text Revision, PCL = PTSD Checklist, PTSD = posttraumatic stress disorder, SEQ-DOD = Sexual Experiences Questionnaire (military version), VA = Department of Veterans Affairs.

*Address all correspondence to Amy E. Street, PhD; National Center for PTSD (116B-3), VA Boston Healthcare System, 150 South Huntington Avenue, Boston, MA 02130; 857-364-5998; fax: 857-364-4515. Email: amy.street@va.gov DOI: 10.1682/JRRD.2007.06.0088
} 
a continuum of behaviors including, at the severe end, those that constitute workplace-based sexual assault.

The Department of Defense's Sexual Harassment Survey (1995), a large-scale investigation of unwanted sexual experiences across all branches of the active duty military, identified high annual occurrences of military sexual harassment and assault. Specifically, 78 percent of women and 38 percent of men reported at least one experience of unwanted sexual behavior generally defined as sexual harassment and 6 percent of women and 1 percent of men reported at least one sexual assault experience during the past year [6]. Lifetime prevalence of military sexual harassment and assault are also high among female veterans who use Department of Veterans Affairs (VA) health services. In one large survey, 55 percent reported that they were sexually harassed and 23 percent reported they were sexually assaulted during military service [2]. Unfortunately, surveys of wartime military samples suggest a similarly high prevalence of military sexual harassment and assault. Among a sample of Army women who served in the 1991 gulf war, 69 percent reported experiencing sexual harassment and 7 percent reported experiencing sexual assault during their war zone service [3].

The high prevalence of sexual harassment and assault reported by active duty military is particularly troubling given the significant negative health consequences often associated with these experiences. In a sample of more than 28,000 active duty men and women, military sexual harassment was associated with poorer psychological well-being and health satisfaction [1]. Among female veterans using VA services, a self-reported history of military sexual harassment or assault was associated with more readjustment problems after discharge (e.g., difficulties finding work, higher rates of substance abuse disorders, poorer general psychological and physical health) [2].

Despite the wealth of evidence demonstrating the high prevalence of sexual harassment and assault and associated negative health consequences among active duty and veteran populations, no previous large-scale investigation has examined these issues among members of the Reserve components of the Armed Forces. This fact represents a significant gap in the knowledge base, because reservists, who serve a minimum of 39 days a year, comprise a significant proportion of U.S. military personnel. Currently, the Reserve forces have approximately 1.1 million members, representing 45 percent of total U.S. military forces [7]. The current investigation
(1) estimated the gender-specific prevalence of experiences of military sexual harassment and sexual assault and (2) identified the negative mental and physical health correlates of these experiences in a sample of former reservists.

\section{METHODS}

\section{Study Population}

The Defense Manpower Data Center (DMDC) provided the names and Social Security numbers of former reservists who, to the best of their knowledge, had not also served in the active duty forces. In the stratified random sampling design, the target population was stratified by gender (oversampling females) and by the seven specific Reserve components (i.e., Army Reserve, Army National Guard, Naval Reserve, Marine Corps Reserve, Air Force Reserve, Air National Guard, and Coast Guard Reserve). A total of 2,338 female reservists participated out of a target of 2,500 (93.5\%), and a total of 1,684 male reservists participated out of a target of 2,000 (84.2\%). After we deleted data from 76 reservists from whom only partial data were available, the final study group consisted of 3,946 former reservists (2,318 females and 1,628 males). All participants had completed military service by December 31, 2000. On average, participants had completed service 9.12 years before data collection. Selected characteristics of survey participants, stratified by sexual harassment/sexual assault status, are presented in Table 1 (females) and Table 2 (males).

\section{Data Collection}

VA Boston Healthcare System's committee on the use of human subjects in research approved the data collection. Location efforts used several address and telephone search services (National Institute for Occupational Safety and Health/Internal Revenue Service, Telematch, Experian Credit Bureau, directory assistance) to identify accurate contact information, resulting in a final sample of 13,032 former reservists, not all of whom were guaranteed to meet study eligibility requirements (i.e., served in the Reserves but did not serve in active duty). Accurate contact information was unavailable on the remainder of the target sample, primarily because of errors in the DMDC database.

Participants were interviewed with a computer-assisted telephone interview protocol during a 7-month period 
Table 1.

Female participants: Demographic and military characteristics stratified by military sexual harassment (SH)/sexual assault (SA) status.

\begin{tabular}{|c|c|c|}
\hline Characteristic & $\begin{array}{c}\text { SH/SA } \\
(\%)\end{array}$ & $\begin{array}{c}\text { No SH/SA } \\
(\%)\end{array}$ \\
\hline \multicolumn{3}{|l|}{ Demographic } \\
\hline \multicolumn{3}{|l|}{ Age at Interview ${ }^{*}$} \\
\hline $20-29$ & 9.0 & 15.0 \\
\hline $30-39$ & 51.7 & 46.0 \\
\hline $40-49$ & 26.1 & 21.5 \\
\hline $50-59$ & 10.3 & 13.2 \\
\hline $60+$ & 2.9 & 4.3 \\
\hline \multicolumn{3}{|l|}{ Race/Ethnicity $^{*}$} \\
\hline White & 67.9 & 63.7 \\
\hline Black/African American & 22.5 & 26.7 \\
\hline Hispanic/Latino & 5.4 & 4.3 \\
\hline Other & 4.2 & 5.3 \\
\hline \multicolumn{3}{|l|}{ Marital Status } \\
\hline Married/Live as Couple & 57.0 & 56.8 \\
\hline Separated/Divorced & 17.8 & 17.4 \\
\hline Widowed & 1.6 & 1.7 \\
\hline Never Married & 23.6 & 24.1 \\
\hline \multicolumn{3}{|l|}{ Income (\$) } \\
\hline$<15,000$ & 7.0 & 6.8 \\
\hline $15,000-34,999$ & 23.0 & 24.5 \\
\hline $35,000-54,999$ & 28.2 & 32.0 \\
\hline $55,000-74,999$ & 19.3 & 16.5 \\
\hline $75,000-94,999$ & 10.5 & 8.2 \\
\hline$>95,000$ & 12.0 & 12.0 \\
\hline \multicolumn{3}{|l|}{ Education $^{*}$} \\
\hline Less than High School & 0.5 & 0.4 \\
\hline High School Graduate & 11.6 & 16.2 \\
\hline Vocational Training & 2.8 & 4.0 \\
\hline Some College & 44.0 & 42.8 \\
\hline College Graduate & 22.8 & 19.7 \\
\hline Graduate/Professional School & 18.3 & 16.9 \\
\hline \multicolumn{3}{|l|}{ Military } \\
\hline \multicolumn{3}{|l|}{ Year First Served ${ }^{* \dagger}$} \\
\hline $1940 s$ & 0.0 & 0.0 \\
\hline $1950 \mathrm{~s}$ & 0.1 & 0.4 \\
\hline 1960s & 0.4 & 0.8 \\
\hline 1970s & 9.5 & 7.7 \\
\hline 1980s & 64.2 & 54.1 \\
\hline 1990s & 25.8 & 36.8 \\
\hline $2000 s$ & 0.0 & 0.2 \\
\hline \multicolumn{3}{|l|}{ Years Served*† } \\
\hline $0-4$ & 29.7 & 37.6 \\
\hline $5-9$ & 51.5 & 45.9 \\
\hline $10-19$ & 16.4 & 13.7 \\
\hline $20-29$ & 2.4 & 2.5 \\
\hline $30-39$ & 0.0 & 0.3 \\
\hline $40+$ & 0.0 & 0.0 \\
\hline \multicolumn{3}{|l|}{ Pay Grade at Discharge } \\
\hline Junior Enlisted & 62.3 & 69.6 \\
\hline Senior Enlisted & 28.2 & 18.2 \\
\hline Officer & 9.5 & 12.2 \\
\hline
\end{tabular}

\begin{tabular}{|c|c|c|}
\hline Characteristic & $\begin{array}{c}\text { SH/SA } \\
(\%)\end{array}$ & $\begin{array}{c}\text { No SH/SA } \\
(\%)\end{array}$ \\
\hline \multicolumn{3}{|l|}{ (Continued) } \\
\hline \multicolumn{3}{|c|}{ Discharged from Reserves/Guard } \\
\hline Honorable & 87.0 & 86.7 \\
\hline General & 11.3 & 10.7 \\
\hline Other than Honorable & 1.7 & 2.6 \\
\hline \multicolumn{3}{|c|}{ Service-Connected Disability Status ${ }^{*}$} \\
\hline Yes & 5.8 & 3.6 \\
\hline No & 94.2 & 96.4 \\
\hline \multicolumn{3}{|c|}{$\begin{array}{l}{ }^{*} p<0.05, p \text { significance probability by chi-square test of independence } \\
\text { between SH/SA assault status. Rows of some characteristics were collapsed to } \\
\text { meet minimum expected cell size required for approximation of chi-square dis- } \\
\text { tribution (i.e., year first served, years served). } \\
{ }^{\dagger} \text { If participant served in more than one Reserve component, this information } \\
\text { refers to component described as primary. }\end{array}$} \\
\hline
\end{tabular}

between August 2002 and March 2003. Advance letters, including prepaid return letters as a mechanism to withdraw, were mailed in waves 2 weeks before initial contact attempts by telephone. Female interviewers made 25 callback attempts to each respondent on different days and at different times over a period of at least 3 months. All participants received a complete study description and gave informed consent before beginning data collection. The interview averaged 40 minutes, but the programmed skip patterns in the computer-assisted interview system allowed interviewers to ask only those questions most relevant to the participant's experiences. The final cooperation rate among participants with known eligibility (i.e., served in the Reserves but did not serve in active duty) was 74.4 percent (calculated by the number of complete interviews divided by the number of complete interviews plus partial interviews plus noninterviews that involved identification of an eligible sample member [8]). As a result of significant errors in the databases from which the target sample was drawn, this cooperation rate reflects the most accurate measure of participation for this study.

\section{Measures}

Participants' experiences of sexual harassment and sexual assault during Reserve service were assessed with a modified military version of the Sexual Experiences Questionnaire (SEQ-DOD), a 24-item measure widely used to assess sexual harassment among the Armed Forces [9]. The SEQ-DOD comprises items measuring four subtypes of sexual harassment: (1) gender harassment-sexist hostility 
Table 2.

Male participants: Demographic and military characteristics stratified by military sexual harassment (SH)/sexual assault (SA) status.

\begin{tabular}{|c|c|c|}
\hline Characteristic & $\begin{array}{c}\text { SH/SA } \\
(\%)\end{array}$ & $\begin{array}{c}\text { No SH/SA } \\
(\%)\end{array}$ \\
\hline \multicolumn{3}{|l|}{$\overline{\text { Demographic }}$} \\
\hline \multicolumn{3}{|l|}{ Age at Interview } \\
\hline 20-29 & 7.1 & 7.3 \\
\hline $30-39$ & 56.0 & 57.6 \\
\hline $40-49$ & 22.1 & 21.1 \\
\hline $50-59$ & 5.2 & 6.0 \\
\hline $60+$ & 9.6 & 8.0 \\
\hline \multicolumn{3}{|l|}{ Race/Ethnicity } \\
\hline White & 77.8 & 81.6 \\
\hline Black/African American & 12.5 & 9.8 \\
\hline Hispanic/Latino & 5.9 & 4.6 \\
\hline Other & 3.8 & 4.0 \\
\hline \multicolumn{3}{|l|}{ Marital Status } \\
\hline Married/Live as Couple & 74.9 & 75.8 \\
\hline Separated/Divorced & 8.2 & 11.4 \\
\hline Widowed & 0.5 & 0.3 \\
\hline Never Married & 16.4 & 12.5 \\
\hline \multicolumn{3}{|l|}{ Income (\$) } \\
\hline$<15,000$ & 3.6 & 3.4 \\
\hline $15,000-34,999$ & 19.8 & 18.9 \\
\hline $35,000-54,999$ & 35.1 & 31.2 \\
\hline $55,000-74,999$ & 19.8 & 17.2 \\
\hline $75,000-94,999$ & 11.2 & 12.8 \\
\hline$>95,000$ & 10.5 & 16.5 \\
\hline \multicolumn{3}{|l|}{ Education } \\
\hline Less than High School & 3.5 & 2.8 \\
\hline High School Graduate & 21.4 & 25.6 \\
\hline Vocational Training & 6.3 & 4.5 \\
\hline Some College & 37.6 & 33.6 \\
\hline College Graduate & 16.3 & 19.0 \\
\hline Graduate/Professional School & 14.9 & 14.5 \\
\hline \multicolumn{3}{|l|}{ Military } \\
\hline \multicolumn{3}{|l|}{ Year First Served* } \\
\hline $1940 s$ & 0.2 & 0.0 \\
\hline 1950s & 5.0 & 4.7 \\
\hline $1960 \mathrm{~s}$ & 3.9 & 3.4 \\
\hline $1970 \mathrm{~s}$ & 7.3 & 7.6 \\
\hline 1980s & 58.6 & 60.2 \\
\hline 1990s & 25.0 & 24.0 \\
\hline $2000 s$ & 0.0 & 0.1 \\
\hline \multicolumn{3}{|l|}{ Years Served* } \\
\hline $0-4$ & 24.4 & 22.8 \\
\hline $5-9$ & 51.4 & 53.4 \\
\hline $10-19$ & 14.4 & 14.3 \\
\hline $20-29$ & 5.9 & 4.9 \\
\hline $30-39$ & 2.8 & 3.7 \\
\hline $40+$ & 1.1 & 0.9 \\
\hline \multicolumn{3}{|l|}{ Pay Grade at Discharge } \\
\hline Junior Enlisted & 59.5 & 61.4 \\
\hline Senior Enlisted & 31.9 & 29.0 \\
\hline Officer & 8.6 & 9.6 \\
\hline
\end{tabular}

\begin{tabular}{lcc}
\hline \multicolumn{1}{c}{ Characteristic } & $\begin{array}{c}\text { SH/SA } \\
(\mathbf{\%})\end{array}$ & $\begin{array}{c}\text { No SH/SA } \\
\mathbf{( \% )}\end{array}$ \\
\hline (Continued) & & \\
Discharged from Reserves/Guard & & \\
$\quad$ Honorable & 85.9 & 85.1 \\
General & 11.8 & 12.6 \\
$\quad$ Other than Honorable & 2.3 & 2.3 \\
Service-Connected Disability Status & & \\
$\quad$ Yes & 3.5 & 3.2 \\
$\quad$ No & 96.5 & 96.8 \\
\hline${ }^{*}$ If participant served in more than one Reserve component, this information \\
refers to component identified as primary. \\
\hline \hline
\end{tabular}

(e.g., made offensive sexist remarks such as suggesting that people of your gender are not suited for the kind of work you do), (2) gender harassment-sexual hostility (e.g., made offensive remarks about your appearance, body, or sexual activities), (3) unwanted sexual attention (e.g., displayed, used, or distributed sexist or suggestive materials such as pictures, stories, or pornography that you found offensive), and (4) sexual coercion (e.g., implied faster promotions or better treatment if you were sexually cooperative). Cronbach $\alpha$ for the SEQ-DOD in the study sample was 0.81 for females and 0.78 for males. This investigation augmented the SEQ-DOD with behaviorally worded items that assessed sexual assault and rape and were originally created for the National Women's Study [10]. Minor modifications to the wording ensured language appropriate to the Reserve context and participants of either gender.

A participant was considered to have experienced sexual harassment if he or she self-reported at least four separate potentially harassing experiences or at least one experience presumed to be more severe (e.g., extortion of sexual cooperation in return for job-related considerations) during his or her Reserve service. This scoring system provides a more stringent prevalence estimate of sexual harassment than if a participant were considered harassed if he or she endorsed experiencing any potentially sexually harassing behavior at any frequency. A participant was considered to have experienced sexual assault if he or she self-reported at least one experience of coerced genital fondling, attempted rape, or completed rape during his or her Reserve service. Given that all experiences occurred in an occupational context, for this investigation sexual assault represents a specific, severe form of sexual harassment. Accordingly, prevalence estimates of sexual harassment include experiences of sexual assault. 
Current symptoms of depression were assessed with the 10-item Center for Epidemiologic Studies Depression Scale (CES-D) [11]. Participants indicated how frequently they had experienced each depression symptom during the past week on a four-point scale ranging from 0 (none of the time to less than 1 day) to 3 (5 to 7 days). All items were summed for a total scale score. Cronbach $\alpha$ was 0.88 for females and 0.86 for males. Participants were considered "depressed" if they met the CES-D recommended cutoff score of 10. Current (past month) and lifetime (anytime since the harassment) symptoms of posttraumatic stress disorder (PTSD) were assessed with the 17-item PTSD Checklist (PCL) [12]. Participants responded to each item on a five-point Likert scale ranging from 1 (not at all) to 5 (extremely) and all items were summed for a total scale score. We used a recommended cutoff of 44 on the PCL to indicate symptoms consistent with a Diagnostic and Statistical Manual of Mental Disorders-Fourth Edition-Text Revision (DSM-IV-TR) diagnosis of PTSD [13]. Cronbach $\alpha$ was 0.93 and 0.95 for females and 0.95 and 0.95 for males for current and lifetime measures, respectively. Because the PCL items were asked in reference to experiences of sexual harassment and assault during military service, participants who did not report these experiences did not complete the PCL.

Somatic symptoms were assessed with a measure created for this investigation. Participants were asked about somatic symptoms in each of the four symptom categories that comprise somatization disorder in the DSM-IV-TR [14]. Items included three items assessing pain symptoms, four items assessing gastrointestinal symptoms, three items assessing psychoneurological symptoms, and two items assessing sexual symptoms. Females were administered two additional unique items about menstrual symptoms, and males were administered one additional unique item about male sexual dysfunction. Participants were asked the extent to which they had experienced each symptom during the last 6 months on a four-point Likert scale ranging from 0 (not at all) to 3 (extremely). Cronbach $\alpha$ was 0.77 for the 14 -item female version and the 13-item male version of the measure. All items were summed for a total scale score. A median split classified participants as high and low somatization (female median $=4.7$, male median $=2.0$ ). Current medical conditions were assessed with a measure created for this investigation. Using a yes/no response format, we asked participants whether they had been bothered by or treated for 14 major medical conditions (e.g., diabetes, hypertension, arthritis, cancer) in the past year. Female participants were administered an additional unique item about medical conditions associated with the reproductive system. All items were summed for a total scale score. A mean split was used to classify participants as high or low (female mean $=1.5476$, male mean $=0.9242)$. Measures of internal consistency were not computed, because they would be inappropriate for a condition-based measure of this type.

\section{Statistical Analysis}

In the sampling design, the target population was stratified by gender and the seven Reserve components. Statistical weights were computed for each stratum. During field operations, classification problems in the population database (the DMDC file) became evident; these problems included ineligibility of sample members and misclassification of stratification variables. Accordingly, the original statistical weights were modified; the modified statistical weights were adopted for the prevalence analyses, a strategy that allowed for confidence in the resulting prevalence estimates. To determine confidence intervals of the estimated prevalence of military sexual harassment and assault, we used the SAS procedure SURVEYFREQ (SAS Institute Inc; Cary, North Carolina), in which the Taylor series expansion method is adopted to estimate sampling errors of estimators based on complex sample designs [15].

Analysis of the possible association between military sexual harassment and assault and mental and physical health correlates began with a simple comparison of the percentages reporting selected outcomes by gender and experience of military sexual harassment or assault. Next, we conducted a series of gender-specific multivariate analyses to examine the health correlates of sexual harassment and assault. For depression, somatic symptoms, and medical conditions, we used two separate logistic models to estimate the adjusted odds ratios (AORs) and 95 percent confidence intervals (CIs) [16]. One model focused on experiences of sexual harassment other than sexual assault, and the other model focused on the combined experience of sexual harassment and sexual assault. "No sexual harassment" served as the reference group for both models. For current and lifetime PTSD symptoms, we used one logistic model to estimate the AOR and CI for the combined experience of sexual harassment and sexual assault, with "sexual harassment only" serving as the reference group. Because this investigation was powered to identify the gender-specific prevalence of sexual harassment and assault rather than 
the lower prevalence of PTSD secondary to sexual harassment and assault, PTSD data were available on an insufficient number of male reservists. Accordingly, logistic regressions predicting PTSD symptoms are reported only for female reservists, the group for which these analyses are sufficiently powered.

In addition to the primary sexual harassment/assault variable, all logistic models included as covariates age (continuous), race (white vs nonwhite) and Reserve component (Naval Reserve, Coast Guard Reserve, and Marine Corps Reserve were combined, creating four indicator variables; Air National Guard was the reference group). Self-report data designed with stratification are usually analyzed by statistical weighting. However, because varying numbers of elements were missing for the health symptoms, the modified weight structure was compromised. Therefore, we retained the stratification variable (Reserve components) as an indicator covariate in our gender-specific logistic regression analyses and handled the data as model-based analyses [17]. Model fit was assessed by the Hosmer and Lemeshow goodness-of-fit test. Any difference was considered significant at $p<$ 0.05. Data analysis was performed with SAS [15].

\section{RESULTS}

\section{Prevalence of Sexual Harassment and Assault}

Population prevalences and 95 percent CIs of sexual harassment and assault by gender and specific Reserve component were estimated (Table 3). Approximately 60.0 percent of all discharged female reservists reported a history of sexual harassment (including assault) during mil- itary service; 13.1 percent reported being sexually assaulted during military service. Among males, the prevalence of both experiences was lower: 27.2 percent for sexual harassment (including assault) and 1.6 percent for sexual assault. Across Reserve components, the prevalence of sexual harassment among females ranged from 57.1 percent (Naval Reserve) to 75.0 percent (Marine Corps Reserve); the prevalence of sexual assault ranged from 6.8 percent (Air Force Reserve) to 15.6 percent (Army National Guard and Air National Guard). Among males, the estimated prevalence of sexual harassment ranged from 21.3 percent (Air National Guard) to 28.7 percent (Army National Guard and Marine Corps Reserve); sexual assault ranged from 0 percent (Naval Reserve, Air National Guard, and Coast Guard Reserve) to 2.9 percent (Air Force Reserve).

\section{Characteristics of Participants Reporting Sexual Harassment or Assault}

Percentage distributions of various characteristics were compared for respondents who reported sexual harassment or assault and those who did not. These comparisons are presented in Table $\mathbf{1}$ for female participants and Table 2 for male participants. Among women, reservists who reported experiencing sexual harassment or assault were more likely (1) overrepresented in younger age categories (specifically age 30-39 and age 40-49, $p<0.001$ ), (2) white ( $p<0.05$ ), (3) more highly educated $(p<0.05)$, (5) to have first served before 1990 $(p<0.001)$, (6) to have served 5 or more years $(p<0.01)$, and (7) to report a service-connected disability $(p<0.05)$ than were those who did not report these experiences. Marital status and type of separation from the Reserves

Table 3.

Estimated population prevalence of military sexual harassment (SH) and sexual assault (SA) in Reserve components.

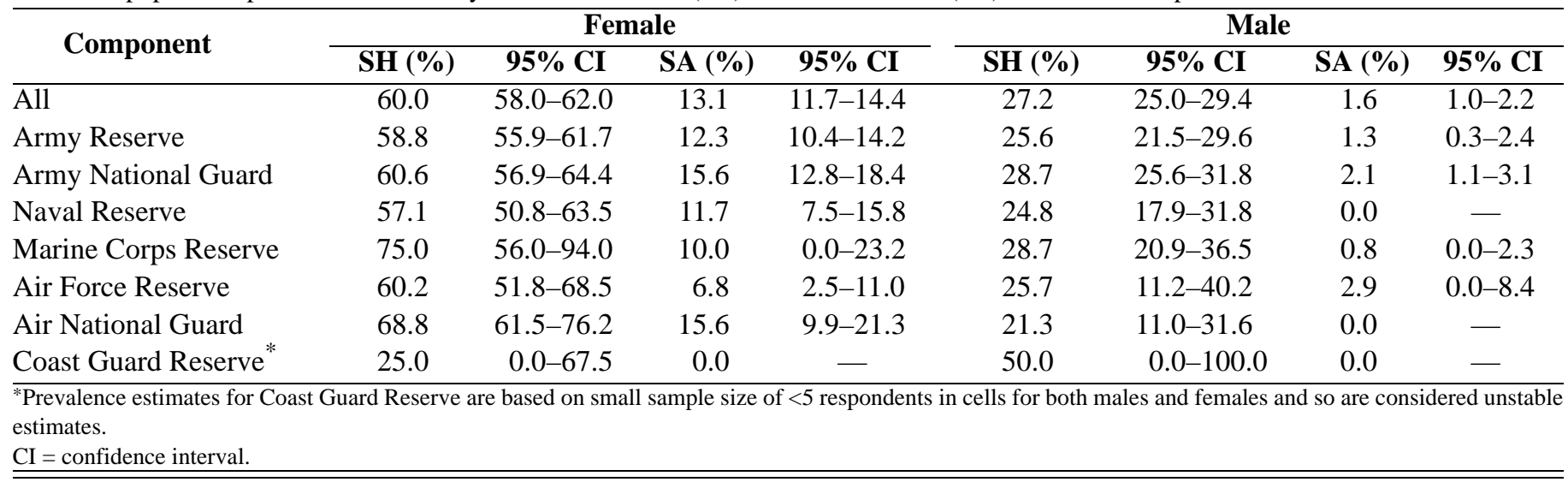


did not differ between the two groups. Male reservists who reported experiences of sexual harassment or sexual assault during service did not differ significantly from those who did not on age, race, marital status, education level attained, first year of service, service duration, type of separation from Reserves, or service-connected disability. All female and male participants who reported experiencing sexual assault also reported experiencing sexual harassment.

\section{Mental and Physical Health Correlates of Sexual Harassment and Assault}

To examine the mental and physical health correlates of sexual harassment and assault, we divided participants into those who reported no sexual harassment/no sexual assault (female $n=924$, male $n=1,189$ ), those who reported sexual harassment only (female $n=1,092$, male $n=414$ ), and those who reported sexual harassment and sexual assault (female $n=302$, male $n=25$ ). Table 4 lists the prevalence of depression, somatic symptoms, medical conditions, and current and lifetime PTSD symptoms by self-reported experiences of sexual harassment and assault. Table 5 presents results of gender-specific logistic regressions examining depression, somatic symptoms, and medical conditions by experiences of sexual harassment and assault. Among females, self-reported experiences of sexual harassment (not including sexual assault) were associated with greater risks of depression $(\mathrm{AOR}=1.75$, $95 \% \mathrm{CI}=1.37-2.24)$, somatic symptoms $(\mathrm{AOR}=1.77$, 95\% CI $=1.48-2.12)$, and medical conditions (AOR = $1.58,95 \%$ CI $=1.31-1.92$ ). Self-reported experiences of both sexual harassment and assault were associated with greater risks of depression $(\mathrm{AOR}=4.51,95 \% \mathrm{CI}=3.30$ 6.16), somatic symptoms (AOR $=3.65,95 \% \mathrm{CI}=2.74$ 4.87), and medical conditions (AOR $=2.83,95 \% \mathrm{CI}=$ 2.14-3.72). Table 6 presents results of logistic regressions examining current and lifetime PTSD symptoms by experiences of sexual harassment and assault among females. When compared with experiences of sexual harassment only, self-reported experiences of sexual harassment and assault were associated with greater risk of current PTSD (AOR $=7.15,95 \% \mathrm{CI}=4.03-12.69)$ and lifetime PTSD $($ AOR $=7.03,95 \%$ CI $=5.05-9.79)$.

Table 4.

Frequency and observed prevalence of depression, somatic symptoms, medical conditions, and current and lifetime posttraumatic stress disorder (PTSD) by reservists' self-reported experiences of military sexual harassment (SH) and sexual assault (SA).

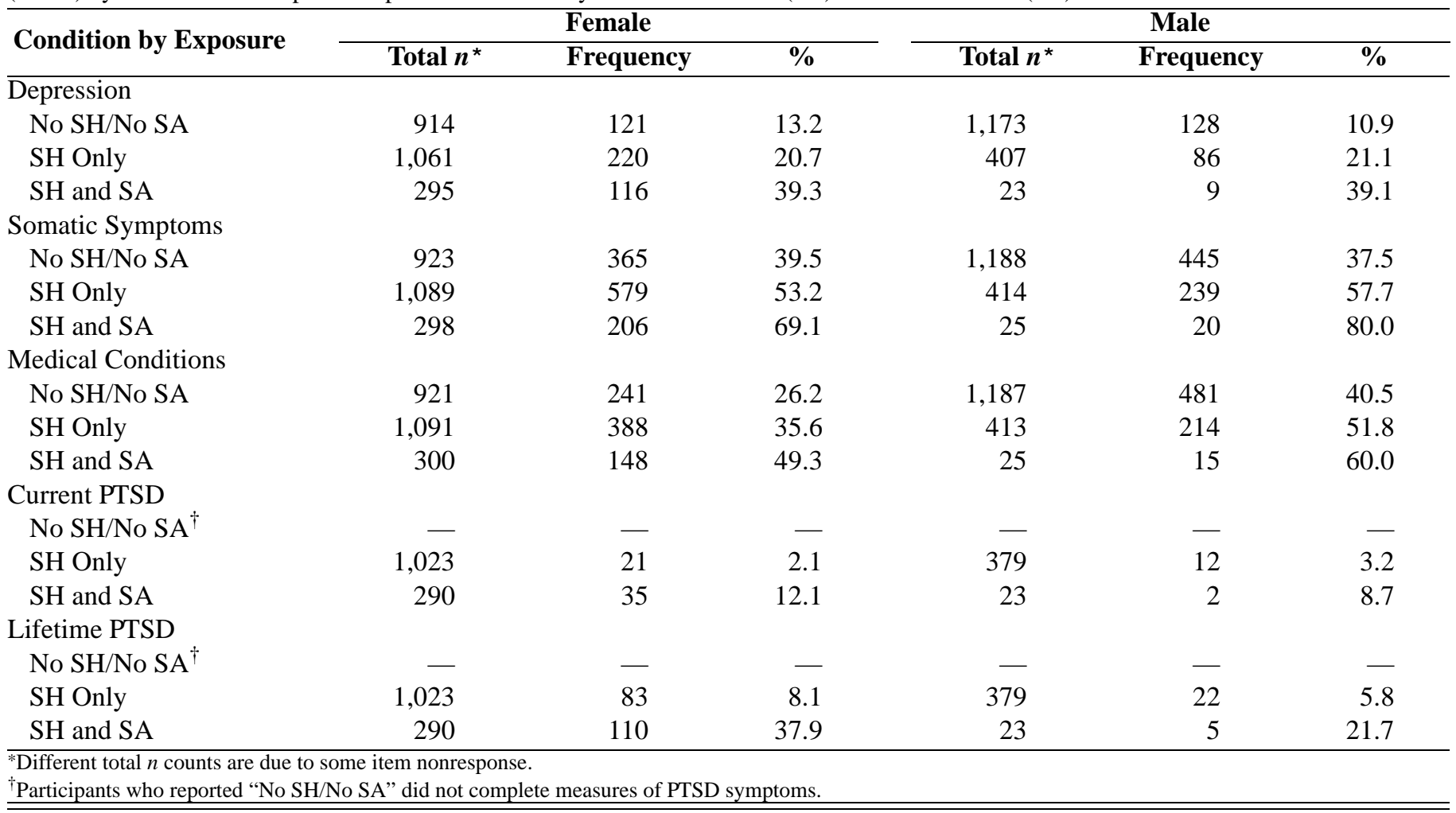


Table 5.

Gender-specific logistic regressions for depression, somatic symptoms, and medical conditions by reservists' self-reported experiences of military sexual harassment (SH) and sexual assault (SA).

\begin{tabular}{|c|c|c|c|c|}
\hline \multirow{2}{*}{ Logistic Model $^{*}$} & \multicolumn{2}{|c|}{ Female } & \multicolumn{2}{|c|}{ Male } \\
\hline & AOR & $95 \% \mathrm{CI}$ & AOR & 95\% CI \\
\hline \multicolumn{5}{|l|}{ Depression } \\
\hline Model 1: SH Only & 1.75 & $1.37-2.24$ & 2.21 & $1.63-2.99$ \\
\hline Model 2: SH and SA & 4.51 & $3.30-6.16$ & 5.38 & $2.21-13.06$ \\
\hline \multicolumn{5}{|l|}{ Somatic Symptoms } \\
\hline Model 1: SH Only & 1.77 & $1.48-2.12$ & 2.27 & $1.81-2.85$ \\
\hline \multicolumn{5}{|l|}{ Medical Conditions } \\
\hline Model 1: SH Only & 1.58 & 1.31-1.92 & 1.59 & $1.26-2.00$ \\
\hline Model 2: SH and SA & 2.83 & $2.14-3.72$ & 2.06 & $0.90-4.71$ \\
\hline \multicolumn{5}{|c|}{$\begin{array}{l}\text { *Logistic models include following covariates: age, race, Reserve component, as well as variable for SH or SA. Model } 1 \text { excludes persons who experienced SA } \\
\text { while serving in Reserve component; model } 2 \text { excludes persons who experienced SH while serving in Reserve component. Reference group is always No SH/No } \\
\text { SA; comparison group for AOR (reference level) among Reserve components is Air Force National Guard for females and males. } \\
\text { AOR = adjusted odds ratio, CI = confidence interval. }\end{array}$} \\
\hline
\end{tabular}

Table 6.

Female-specific logistic regressions for current and lifetime posttraumatic stress disorder (PTSD) by female reservists' self-reported experiences of military sexual harassment (SH) and sexual assault (SA).

\begin{tabular}{lcc}
\hline Logistic Model* $^{*}$ & AOR & 95\% CI \\
\hline $\begin{array}{l}\text { Current PTSD } \\
\text { SH and SA }\end{array}$ & 7.15 & $4.03-12.69$ \\
$\begin{array}{l}\text { Lifetime PTSD } \\
\text { SH and SA }\end{array}$ & 7.03 & $5.05-9.79$ \\
\hline
\end{tabular}

${ }^{*}$ Logistic models include following covariates: age, race, Reserve component, as well as variable for SH and SA. Models exclude participants who reported "No SH/No SA" because they did not complete PTSD symptom measures. Reference group is SH Only and comparison group for AOR (reference level) among Reserve components is Air Force National Guard.

$\underline{\mathrm{AOR}=\text { adjusted odds ratio, } \mathrm{CI}=\text { confidence interval. }}$

Among males (Table 5), self-reported experiences of sexual harassment (not including sexual assault) were associated with greater risks of depression $(\mathrm{AOR}=2.21$, $95 \% \mathrm{CI}=1.63-2.99)$, somatic symptoms $(\mathrm{AOR}=2.27$, $95 \% \mathrm{CI}=1.81-2.85$ ), and medical conditions (AOR = $1.59,95 \% \mathrm{CI}=1.26-2.00)$. Self-reported experiences of both sexual harassment and assault were strongly associated with depression (AOR $=5.38,95 \% \mathrm{CI}=2.21-13.06)$ and somatic symptoms $(\mathrm{AOR}=6.33,95 \% \mathrm{CI}=2.34$ 17.08). Inclusion of age, race, and Reserve component as covariates in the regression model did not change the univariate relationship between experiencing both sexual harassment and assault and medical conditions (AOR = 2.06, 95\% CI $=0.90-4.71$ ). Logistic regressions predicting PTSD symptoms among male reservists were not sufficiently powered and therefore are not reported.

\section{DISCUSSION}

This investigation represents the first comprehensive effort to identify the prevalence of military sexual harassment and assault among members of the Reserve Forces. Both men and women had a substantial prevalence of military sexual harassment and assault. As expected, higher proportions of female reservists reported sexual harassment (60.0\% vs $27.2 \%$ for males) and sexual assault (13.0\% vs $1.6 \%$ for males). However, given the greater number of male reservists, population estimates of reservists experiencing unwanted sexual or genderbased attention are greater for men than for women (approximately 63,700 females vs 123,400 males). The same does not hold for sexual assault (approximately 13,900 females vs 7,100 males were assaulted). While a significant body of research has documented a high prevalence of sexual harassment and assault among active duty samples, this investigation is the first to document a similarly high prevalence among members of the Reserve components of the Armed Forces.

An additional goal of this investigation was to identify associations between experiences of military sexual harassment and assault and current mental and physical health. For both men and women these experiences were associated with deleterious health conditions, with sexual assault usually having stronger associations than other types of sexual harassment. Almost a decade after service (on average), reservists with these experiences reported significantly poorer health status than other reservists. 
This investigation is unique in demonstrating these associations among a sample of reservists for whom military service was not a full-time job and who therefore had limited contact with the occupational setting. Further, while the negative health consequences of sexual harassment and assault have been well documented among women, this investigation adds to a small but growing body of literature documenting deleterious health consequences in the wake of sexual harassment and assault among men. While the statistical analyses presented here do not directly test gender differences in these associations, other investigations among this sample of reservists suggest that associations between sexual harassment and mental health symptoms may actually be stronger for men than for women [18].

One must consider several important caveats when interpreting these results. First, our sample was drawn from the population of former reservists who served primarily from 1980 to 2000 and who spent very little time on active duty. While these results provide important evidence for the prevalence of military sexual harassment and assault among this population, the results should not be generalized beyond this population to current members of the Reserve Forces.

In addition, the term sexual harassment can encompass a wide range of behaviors, some of which may be relatively common experiences in the workplace (e.g., "told sexual stories or jokes ... offensive to you"), while others are less so (e.g., "threatened you . . . for not being sexually cooperative"). Accordingly, self-report measures of sexual harassment such as the ones used in this investigation cannot identify whether the reported behaviors would meet a legal standard of sexual harassment or whether these experiences rise to the level of a Criterion A experience necessary for a diagnosis of PTSD as outlined by the DSM-IV-TR [14]. The experiences of some participants likely meet these standards while others do not; the measurement used in this investigation does not allow us to explore this issue in a more detailed way. Experiences of sexual harassment and assault were, by necessity, assessed through unverified retrospective selfreports of experiences during military service and so are subject to numerous limitations, including recall bias and systematic response distortions. Because participants answered questions about experiences that occurred a number of years before, concerns about the validity of responses exist but are mitigated by consistency with a number of other investigations of unwanted sexual experiences in military samples.

Finally, because this investigation used cross-sectional data, the statistical association of sexual harassment and assault with negative health conditions must be interpreted with some caution. While we hypothesize that exposure to sexual harassment and assault during military service led to increased mental and physical health symptoms, these symptoms may have predated the sexual harassment, either serving as a risk factor for the occurrence of harassment or causing some individuals to differentially perceive workplace interactions as harassing. Alternatively, unmeasured intervening variables may account for the demonstrated associations between the variables of interest. Future research is needed to elucidate the causal nature of these associations.

Despite these limitations, these data extend previous evidence that sexual harassment during military service represents a significant problem with implications for the mental and physical well-being of both male and female members of the U.S. military. Given the high prevalence identified here, incorporating assessment of military sexual harassment and assault and any health symptoms associated with these events into standard evaluations conducted at VA hospitals is appropriate, particularly in settings that address trauma-related psychological symptoms. In fact, VA policy mandates that any veteran receiving VA services be screened for a history of sexual trauma and that this screening be documented in the veteran's electronic medical record, a policy with demonstrated feasibility and effectiveness [19-20].

While the experiences of reservists have been overlooked in previous investigations, these prevalence estimates indicate that despite part-time service, experiences of sexual harassment and assault are likely to impact a substantial number of members of the Reserve Forces, perhaps with long-lasting deleterious effects. This issue is important to VA healthcare providers because public law allows reservists who experienced military sexual trauma to seek free care for associated mental and physical health conditions from VA hospitals regardless of whether they would otherwise be eligible for VA care [21].

Our investigation did not address organizational or individual antecedents for sexual harassment or assault. However, the high prevalence of these experiences across a range of military samples plus the personal and financial costs of these experiences to individuals, our healthcare systems, and U.S. military forces [22] indicate that 
future research must identify these antecedents to move toward the critical goal of preventing military sexual harassment and assault.

\section{CONCLUSIONS}

Results of this investigation, the first comprehensive effort to identify the prevalence of military sexual harassment and assault among members of the Reserve Forces, revealed a substantial prevalence of military sexual harassment and assault. For both men and women, these experiences were associated with deleterious mental and physical health conditions, with sexual assault demonstrating stronger associations in most cases. These data provide further evidence that experiences of sexual harassment and assault during military service have significant implications for the treatment needs of VA healthcare users.

\section{ACKNOWLEDGMENTS}

We wish to thank Tamara Bruce, Stephanie Clarke, and Kacie Kelly for assistance with data collection, data cleaning, and report preparation. We would also like to acknowledge Dr. Han K. Kang for consultation regarding the sample size and data analytic strategy and Drs. Paula Schnurr and Matt Friedman for consultation regarding study design and data analytic strategy.

This material was based on work supported by an award from the VA Women Veterans Health Program.

The views, opinions, and/or findings contained in this article are the authors' and do not necessarily represent the views of the VA.

The authors have declared that no competing interests exist.

\section{REFERENCES}

1. Fitzgerald LF, Drasgow F, Magley VJ. Sexual harassment in the Armed Forces: A test of an integrated model. Mil Psychol. 1999;11(3):329-43.

2. Skinner KM, Kressin N, Frayne S, Tripp TJ, Hankin CS, Miller DR, Sullivan LM. The prevalence of military sexual assault among female Veterans' Administration outpatients. J Interpers Violence. 2000;15(3):291-310.
3. Wolfe J, Sharkansky EJ, Read JP, Dawson R, Martin JA, Ouimette PC. Sexual harassment and assault as predictors of PTSD symptomatology among U.S. female Persian Gulf War military personnel. J Interpers Violence. 1998;13(1): 40-57.

4. Fitzgerald LF, Shullman SL, Bailey N, Richards M, Swecker J, Gold A, Ormerod AJ, Weitzman L. The incidence and dimensions of sexual harassment in academia and the workplace. J Vocat Behav. 1988;32(2):152-75.

5. U.S. Equal Employment Opportunity Commission [homepage on the Internet]. Washington (DC): EEOC; c1994-2008 [updated 1999 Jun 21; cited 2006 Apr 13] Policy guidance on current issues of sexual harassment; [1 screen]. Available from: http://www.eeoc.gov/policy/docs/currentissues.html

6. Bastian LD, Lancaster AR, Reyest HE. Department of Defense 1995 sexual harassment survey. Washington (DC): Department of Defense; 1996.

7. Office of the Assistant Secretary of Defense for Reserve Affairs (OASD/RA). Information Briefing, March 13, 2006 [monograph on the Internet]. Washington (DC): OASD/ RA; 2006 [cited 2006 April 13]. Available from: http:// www.defenselink.mil/ra/documents/RA101FY06.pdf

8. American Association for Public Opinion Research. Standard definitions: Final dispositions of case codes and outcome rates for surveys. 4th ed. Ann Arbor (MI): American Association for Public Opinion Research; 2005.

9. Fitzgerald LF, Magley VJ, Drasgow F, Waldo CR. Measuring sexual harassment in the military: The Sexual Experiences Questionnaire (SEQ-DOD). Mil Psychol. 1999;11(3): 243-63.

10. Kilpatrick DG, Edmunds CN, Seymour AK. Rape in America: A report to the nation. Arlington (VA): National Victim Center and Medical University of South Carolina; 1992.

11. Joseph S, Lewis CA. Factor analysis of the Center for Epidemiological Studies-Depression scale. Psychol Rep. 1995; 76(1):40-42. [PMID: 7770591]

12. Weathers FW, Litz BT, Herman DS, Huska JA, Keane TM. The PTSD Checklist (PCL): Reliability, validity, and diagnostic utility. In: Proceedings of the International Society for Traumatic Stress Studies; 1993 Oct 25; San Antonio, Texas.

13. Ruggiero KJ, Del Ben K, Scotti JR, Rabalais AE. Psychometric properties of the PTSD Checklist-Civilian Version. J Trauma Stress. 2003;16(5):495-502. [PMID: 14584634]

14. American Psychiatric Association. Diagnostic and statistical manual of mental disorders. 4th ed-text revision. Washington (DC): American Psychiatric Association; 2000.

15. Clark V. SAS/STAT 9.1: User's guide. Cary (NC): SAS Institute Inc; 2004.

16. Selvin S. Statistical analysis of epidemiologic data. New York (NY): Oxford University Press; 1991.

17. Hosmer DW, Lemeshow S. Applied logistic regression. 2nd ed. New York (NY): Wiley; 2000. 
18. Street AE, Gradus JL, Stafford J, Kelly K. Gender differences in experiences of sexual harassment: Data from a male-dominated environment. J Consult Clin Psychol. 2007; 75(3):464-74. [PMID: 17563163]

19. Kimerling R, Gima K, Smith MW, Street A, Frayne S. The Veterans Health Administration and military sexual trauma. Am J Public Health. 2007;97(12):2160-66. [PMID: 17971558]

20. Kimerling R, Street AE, Gima K, Smith MW. Evaluation of universal screening for military-related sexual trauma. Psychiatr Serv. In press 2008.
21. Veterans Health Programs Improvement Act of 2004. Pub. L. No. 108-422, 118 Stat. 2379 (November 30, 2004).

22. Knapp DE, Kustin GA. The real "disclosure”: Sexual harassment and the bottom line. In: Stockdale MS, editor. Sexual harassment in the workplace: Perspectives, frontiers, and response strategies. Thousand Oaks (CA): Sage; 1996. p. 199-213.

Submitted for publication June 19, 2007. Accepted in revised form December 12, 2007. 